\title{
High carriage of adherent invasive E. coli in wildlife and healthy individuals
}

\author{
Oumaïra Rahmouni ${ }^{1}$, Cécile Vignal ${ }^{1}$, Marie Titécat ${ }^{1,2}$, Benoît Foligné ${ }^{1}$, Benjamin Pariente ${ }^{1,3}$, Laurent Dubuquoy ${ }^{1}$, \\ Pierre Desreumaux ${ }^{1,3}$ and Christel Neut ${ }^{1,4^{*}}$
}

\begin{abstract}
Background: Adherent invasive Escherichia coli (AIEC) are suspected to be involved in the pathogenesis of inflammatory bowel diseases. Since AIEC was first described in 1999, despite important progress on its genomic and immune characterizations, some crucial questions remain unanswered, such as whether there exists a natural reservoir, or whether there is asymptomatic carriage. The ECOR collection, including E. coli strains isolated mainly from the gut of healthy humans and animals, constitutes an ideal tool to investigate AIEC prevalence in healthy condition. A total of 61 E. coli strains were examined for characteristics of AIEC.
\end{abstract}

Methods: The adhesion, invasion and intramacrophage replication capabilities (AIEC phenotype) of 61 intestinal $E$. coli strains were determined. The absence of virulence-associated diarrheagenic E. coli pathotypes (EPEC, ETEC, EIEC, EHEC, DAEC, EAEC), and uropathogenic E. coli was checked.

Results: Out of 61 intestinal strains, 13 (21\%) exhibit the AIEC phenotype, 7 are from human origin and 6 are from animal origin. Prevalence of AIEC strains is about 24 and 19\% in healthy humans and animals respectively. These strains are highly genetically diverse as they are distributed among the main described phylogroups. Among E. coli strains from the ECOR collection, we also detected strains able to detach I-407 cells.

Conclusions: Our study described for the first time AIEC strains isolated from the feces of healthy humans and animals.

Keywords: Adherent invasive Escherichia coli (AIEC), Healthy individuals, ECOR collection, Pathobiont

\section{Background}

Crohn's disease $(\mathrm{CD})$, one of the clinical presentation of inflammatory bowel diseases (IBD), is characterized by chronic lesions of varying intensity along the gastrointestinal tract resulting from an exacerbated reaction of a defective immune system [1-3]. The etiology of CD is complex and is multifactorial, one of these factors is the state of the intestinal microbiota [4]. Over the last 20 years, Escherichia coli has attracted the most attention in respect to $C D$ etiology. A high mucosal colonization level by $E$. coli was first demonstrated in CD [5]. A new pathogenic group of $E$. coli, called adherent invasive $E$.

\footnotetext{
*Correspondence: christelneut@nordnet.fr

${ }^{4}$ Laboratoire de Bactériologie, 3, Rue de Pr. Laguesse, B.P. 83, 59006 Lille Cedex, France

Full list of author information is available at the end of the article
}

coli (AIEC), harboring adhesive and invasive abilities to intestinal epithelial cells, was described [6-8]. The main characteristics of AIEC are (i) the ability to adhere to and invade intestinal epithelial cells, (ii) the ability to survive and replicate expansively within macrophages without triggering host cell death, and (iii) the lack of known invasive determinants [10].

The AIEC strains isolated to date are clonally diverse and belong to distinct serotypes [9-11]. The B2 phylogroup is most prevalent, but strains of $\mathrm{A}, \mathrm{B} 1$, and $\mathrm{D}$ phylogroups have also been isolated [8, 10, 12, 13]. AIEC strains have virulence factors in common with other pathogenic $E$. coli and are closely related to extra-intestinal pathogenic E. coli (ExPEC), associated with urinary tract infections and neonatal meningitis [14, 15]. In absence of common and specific genetic signatures between AIEC strains, this pathotype can up to now 
only be identified by phenotypical traits. AIEC have been described in other human intestinal disorders such as ulcerative colitis (UC), another form of IBD, and colorectal cancer but also in animals with intestinal diseases [16-18]. However, AIEC carriage is not restricted to intestinal inflammatory conditions and AIEC have also been found in biopsies of patients with functional intestinal disorders and in asymptomatic subjects undergoing surveillance colonoscopy, subjects termed as "healthy" in AIEC prevalence studies $[6,9,12,13,16]$. A better knowledge of AIEC carriage in healthy condition whether in human or animals will help in understanding more about AIEC natural reservoir and transmission.

The aim of this work was to determine if AIEC is present in the E. coli Reference (ECOR) Collection. The ECOR collection is a set of $E$. coli strains of natural origin, isolated from the gastrointestinal tract of healthy humans and non-human mammalians from a variety of geographic locations, and designed to represent the variation and genetic structure of $E$. coli in natural populations [19]. 61 ECOR strains were isolated from feces of healthy hosts (Table 1), making this collection an ideal tool to study the prevalence of AIEC in healthy conditions.

\section{Results \\ Adherent and invasive capacity of ECOR strains isolated from the feces of healthy individuals}

The ECOR collection contains 61 strains of fecal origin. Of these, 29 were from human and 32 from animals (Table 1). An invasion assay was performed on these strains using I-407 cells based on gentamicin protection, according to previously described methods $[6,15,21$, 22]. All of the strains were first tested for their susceptibility to gentamicin using disc diffusion method as only strains susceptible to gentamicin can be tested. All the strains were found to be susceptible to gentamicin, determined as a zone diameter superior to $17 \mathrm{~mm}$, according to EUCAST recommendations.

The invasion levels of the noninvasive references $E$. coli strain K-12 C600 and E. coli Nissle were $0.0561 \pm 0.0373 \%$ and $0.0254 \pm 0.0265 \%$ respectively. Reference strain LF82, included in all of the assays as a positive invasive control, gave a mean invasion level of $1.0101 \pm 0.9880 \%$. Another positive invasive control $E$. coli NRG857c showed a mean invasion of $0.1683 \pm 0.0368 \%$. The invasion levels were done in triplicate.

Among strains belonging to the ECOR collection, 18 strains $(30 \%)$ were classified as invasive based on this assay, with invasion rates ranging between 0.10 and $0.64 \%$. Eight of these were of human origin $(28 \%)$, four belonged to the phylogroup A (ECOR 1, 2, 9 and 15), one to phylogroup B2 (ECOR 63), two to phylogroup D
(ECOR 35 and ECOR 36) and one to the phylogroup E (ECOR 43). Ten were of animal origin (31\%), two belonging to the phylogroup A (ECOR 7 and 23), four to the phylogroup B1 (ECOR 45, 67, 69 and 70), two to the phylogroup B2 (ECOR 52 and 57) and two to the phylogroup D (ECOR 44 and 46) (Fig. 1).

During the invasion assay, for five of the strains, an unexpected pathogenic feature was discovered: the ability to detach intestinal cells from the microplate. All of these strains were of human origin, one belonging to the phylogroup A (ECOR 6) and the 4 others to the phylogroup B2 (ECOR 51, 53, 54 and 59) (Table 3). Invasion scores of these cell-detaching strains were established but were not interpretable due to their capacity to detach adherent cells from the microplate. The actual concentration of the intracellular bacteria was therefore skewed. Further investigations are necessary to define their propensity to invade.

The strains revealed as invasive were tested for their ability to adhere. All the invasive strains from the ECOR collection were adherent, with an adhesion index ranging between 67 and 334, all showed an adhesion index superior to 1 bacteria per cell (Table 3 ).

\section{Virulence genotyping of the invasive strains and cell-detaching strains}

The 18 fecal strains previously classified as adherent and invasive were genotyped. The presence of 12 selected virulence genes associated with diarrheagenic E. coli pathotype was assessed. This included common virulence factors present in diarrheagenic E. coli pathotypes EHEC (stx-1, stx-2, eae and ehxA), EIEC (ipaC), ETEC (estA, elt and tia), EPEC (eae, ehxA, bfpA), EAEC (aggR and pCVD432) and DAEC ( $a f a D)$ (Additional file 1: Table S1). Three strains were positive for the tia gene (ECOR 57) and tia and $a f a D$ genes (ECOR 63 and 70). These strains are not affiliated as AIEC pathovars and belong to ETEC/ DAEC pathovars. The other 15 invasive strains (ECOR 1 , $2,9,15,35,36,43,7,23,45,67,69,52,44,46)$ were negative for the tested virulence genes excluding their affiliation to the previously described pathotypes (Table 2).

The cell-detaching strains were also tested for their expression of virulence genes associated of enteropathogenic strains. The ECOR 51 strain was shown to express the $a f a D$ virulence gene, showing that this strain is classified as a DAEC. The other cell-detaching strains were negative for the tested genes (Table 2).

\section{Survival and replication ability of the invasive strains from the ECOR collection}

The 15 strains revealed as adherent and invasive and without virulence genes associated with diarrheagenic $E$. coli pathotype were tested for their ability to survive and 
Table 1 Fecal strains investigated in this study

\begin{tabular}{|c|c|c|c|c|c|c|c|c|c|c|c|}
\hline \multirow[t]{2}{*}{ ID } & \multirow[t]{2}{*}{ Serotype } & \multirow[t]{2}{*}{ Phylogroup } & \multicolumn{3}{|l|}{ Source } & \multirow[t]{2}{*}{ ID } & \multirow[t]{2}{*}{ Serotype } & \multirow[t]{2}{*}{ Phylogroup } & \multicolumn{3}{|l|}{ Source } \\
\hline & & & Host & Sex & Location & & & & Host & Sex & Location \\
\hline ECOR1 & ON:HN & A & Human & Woman & USA & ECOR34 & O88:NM & B1 & Dog & & USA \\
\hline ECOR2 & ON:H32 & $A$ & Human & Man & USA & ECOR35 & O1:NM & $\mathrm{D}$ & Human & Man & USA \\
\hline ECOR3 & O1:NM & A & Dog & & USA & ECOR36 & O79:H25 & $\mathrm{D}$ & Human & Woman & USA \\
\hline ECOR4 & ON:HN & A & Human & Woman & USA & ECOR37 & ON:HN & $\mathrm{E}$ & Marmoset & & USA \\
\hline ECOR5 & O79:NM & A & Human & Woman & USA & ECOR38 & O7:NM & $\mathrm{D}$ & Human & Woman & USA \\
\hline ECOR6 & ON:NM & A & Human & Man & USA & ECOR39 & O7:NM & $\mathrm{D}$ & Human & Woman & Sweden \\
\hline ECOR7 & O85:HN & A & Orangutan & & USA & ECOR41 & O7:NM & $\mathrm{D}$ & Human & Man & Tonga \\
\hline ECOR8 & O86:HN & A & Human & Woman & USA & ECOR42 & ON:H26 & $E$ & Human & Man & USA \\
\hline ECOR9 & ON:NM & A & Human & Woman & Sweden & ECOR43 & ON:HN & $\mathrm{E}$ & Human & Woman & Sweden \\
\hline ECOR10 & $\mathrm{O} 6: \mathrm{H} 10$ & A & Human & Woman & USA & ECOR44 & ON:HN & $\mathrm{D}$ & Cougar & & USA \\
\hline ECOR12 & O7:H32 & A & Human & Woman & Sweden & ECOR45 & ON:HM & B1 & Pig & & Indonesia \\
\hline ECOR13 & ON:HN & A & Human & Woman & Sweden & ECOR46 & $\mathrm{O} 1: \mathrm{H} 6$ & $\mathrm{D}$ & Celebese ape & & USA \\
\hline ECOR15 & O25:NM & A & Human & Woman & Sweden & ECOR47 & OM:H18 & $\mathrm{D}$ & Sheep & & New Guinea \\
\hline ECOR16 & ON:H10 & A & Leopard & & USA & ECOR49 & O2:NM & $\mathrm{D}$ & Human & Woman & Sweden \\
\hline ECOR17 & O106:NM & A & Pig & & Indonesia & ECOR51 & $\mathrm{O} 25: \mathrm{HN}$ & B2 & Human infant & & USA \\
\hline ECOR18 & O5:NM & A & Celebese ape & & USA & ECOR52 & $\mathrm{O} 25: \mathrm{H} 1$ & B2 & Orangutan & & USA \\
\hline ECOR19 & $\mathrm{O} 5: \mathrm{HN}$ & A & Celebese ape & & USA & ECOR53 & $\mathrm{O} 4: \mathrm{HN}$ & B2 & Human & Woman & USA \\
\hline ECOR20 & O89:HN & A & Steer & & Bali & ECOR54 & $\mathrm{O} 25: \mathrm{H} 1$ & B2 & Human & & USA \\
\hline ECOR21 & O121:HN & A & Steer & & Bali & ECOR56 & $\mathrm{O} 6: \mathrm{H} 1$ & B2 & Human & Woman & Sweden \\
\hline ECOR22 & ON:HN & A & Steer & & Bali & ECOR57 & ON:NM & B2 & Gorilla & & USA \\
\hline ECOR23 & O86:H43 & A & Elephant & & USA & ECOR58 & O112:H8 & B1 & Lion & & USA \\
\hline ECOR24 & 015:NM & A & Human & Woman & Sweden & ECOR59 & $\mathrm{O} 4: \mathrm{H} 40$ & B2 & Human & Man & USA \\
\hline ECOR25 & ON:HN & A & Dog & & USA & ECOR61 & O2:NM & B2 & Human & Woman & Sweden \\
\hline ECOR26 & O104:H21 & B1 & Human infant & & USA & ECOR63 & ON:NM & B2 & Human & Woman & Sweden \\
\hline ECOR27 & O104:NM & B1 & Giraffe & & USA & ECOR65 & ON:H10 & B2 & Celebese ape & & USA \\
\hline ECOR28 & O104:NM & B1 & Human & Woman & USA & ECOR66 & O4:H40 & B2 & Celebese ape & & USA \\
\hline ECOR29 & O150:H21 & $\mathrm{B} 1$ & Kangaroo rat & & USA & ECOR67 & O4:H43 & B1 & Goat & & Indonesia \\
\hline ECOR30 & $\mathrm{O} 113: \mathrm{H} 21$ & B1 & Bison & & Canada & ECOR68 & ON:NM & B1 & Giraffe & & USA \\
\hline ECOR31 & O79:H43 & $E$ & Leopard & & USA & ECOR69 & ON:NM & B1 & Celebese ape & & USA \\
\hline ECOR32 & $\mathrm{O} 7: \mathrm{H} 21$ & B1 & Giraffe & & USA & ECOR70 & O78:NM & B1 & Gorilla & & USA \\
\hline ECOR33 & O7:H21 & B1 & Sheep & & USA & & & & & & \\
\hline
\end{tabular}

This table was build according to data from previously published papers $[19,20]$

replicate within macrophages. Among these strains, 13 were able to survive and replicate in macrophages. The percent intracellular bacteria at 1 and $24 \mathrm{~h}$ postinfection ranged between 114.06 and $881.36 \%$. The ECOR 1, 2, 9, $15,35,36,43,23,45,67,69,52,44$ were thus considered as belonging to the AIEC pathotype.

The two other strains (ECOR 46 and 7) were not able to replicate inside macrophages with an index of 70.42 and $74.51 \%$ respectively (Table 3 ). These strains were thus not affiliated to the AIEC pathovar.

\section{Discussion}

The ECOR collection is a collection of $E$. coli that reflects the genetic diversity of non-pathogenic $E$. coli isolated from humans and animals of diverse geographical origins [19] (Table 1). We studied the 61 strains of E. coli isolated from the feces of healthy individuals for an invasive phenotype. Our study allowed the demonstration of the presence of AIEC strains in feces of healthy individuals. On the other hand this also gave an insight into the prevalence of AIEC in diverse conditions. Our results showed 


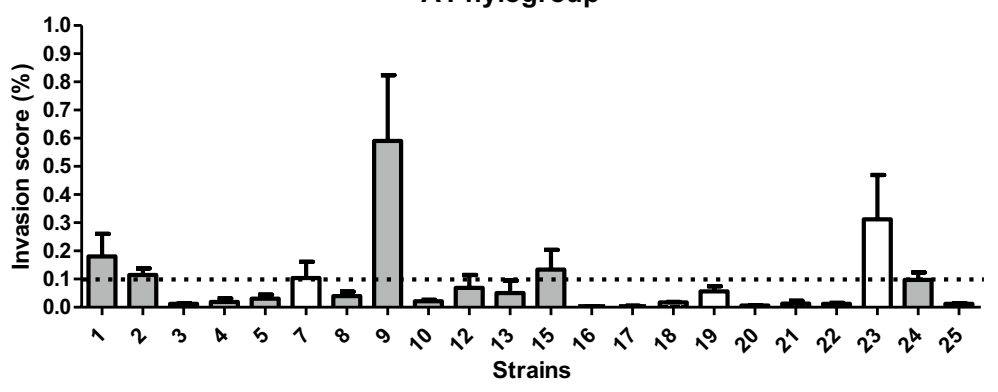

B1 Phylogroup
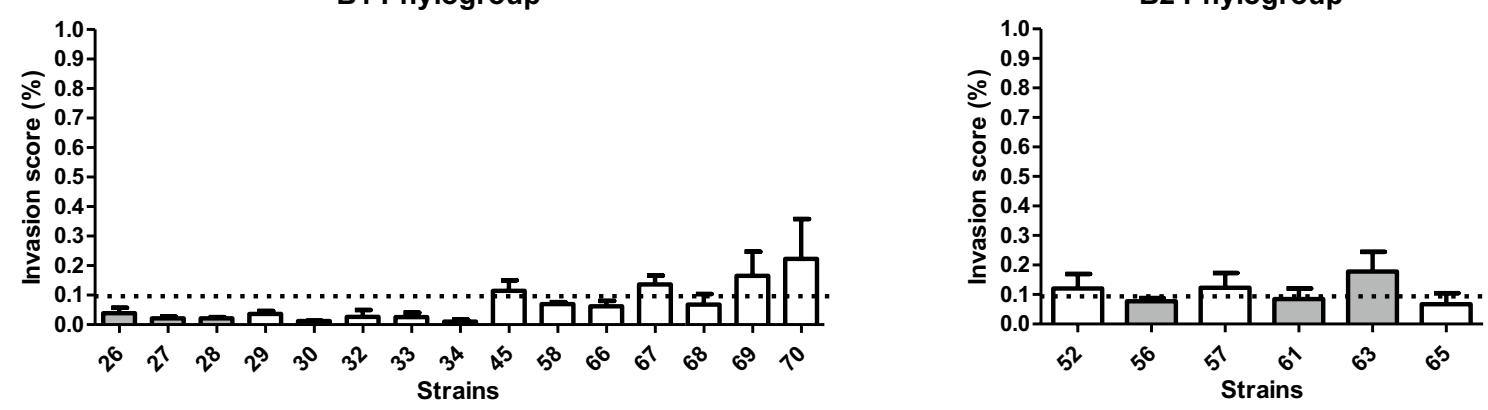

D Phylogroup
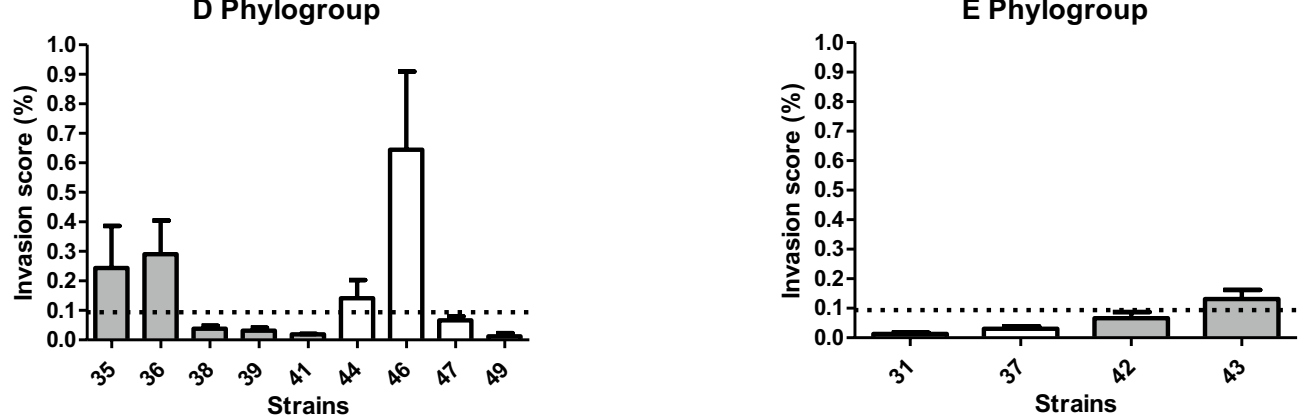

Fig. 1 Invasion score of ECOR strains of fecal origin according to their phylogroup (excluding the cell-detaching strains)

that intestinal E. coli from the ECOR collection could be divided into three groups according to their phenotypes observed in vitro in I-407 cells: (i) non-invasive strains, (ii) invasive strains defined as AIEC and (iii) strains able to disrupt I-407 cell layer.

Of a total of $61 \mathrm{fecal} E$. coli strains, 48 were not invasive, 18 presented adherent and invasive properties and 5 were able to detach I- 407 cells. Out of 18 adherent and invasive strains, 13 were able to survive and replicate inside macrophages, these strains were thus affiliated to the AIEC pathotype. Among all the fecal strains, the prevalence of AIEC was $21 \%$ (24\% in the human set and $19 \%$ among animal strains). All cell-detaching strains were of human origin, which accounted for $8 \%$ of the strains among animal and human isolates $(17 \%$ of all human strains tested).
The AIEC pathotype was first described in inflammatory bowel diseases patients. Several independent research groups have reported a higher prevalence of AIEC in biopsies from IBD patients compared to non-IBD controls. However, AIEC prevalence greatly varies between studies. Indeed, AIEC prevalence was shown to range between 10 and $52 \%$ in ileal biopsies of CD patients [9-12]. This decreases to $3.7 \%$ in colonic biopsies of CD patients, and AIEC has yet to be isolated from colonic biopsies of UC patients [6]. In non-IBD controls, AIEC prevalence was shown to be between 0 and $17 \%$ [9-12]. In our study, we showed for the first time that AIEC strains can also be detected in stools of healthy subjects, with a prevalence of $21 \%$.

AIEC pathovars from the ECOR collection are genetically highly diverse as they belong to different phylogroups. Indeed, among the 13 intestinal adherent and 


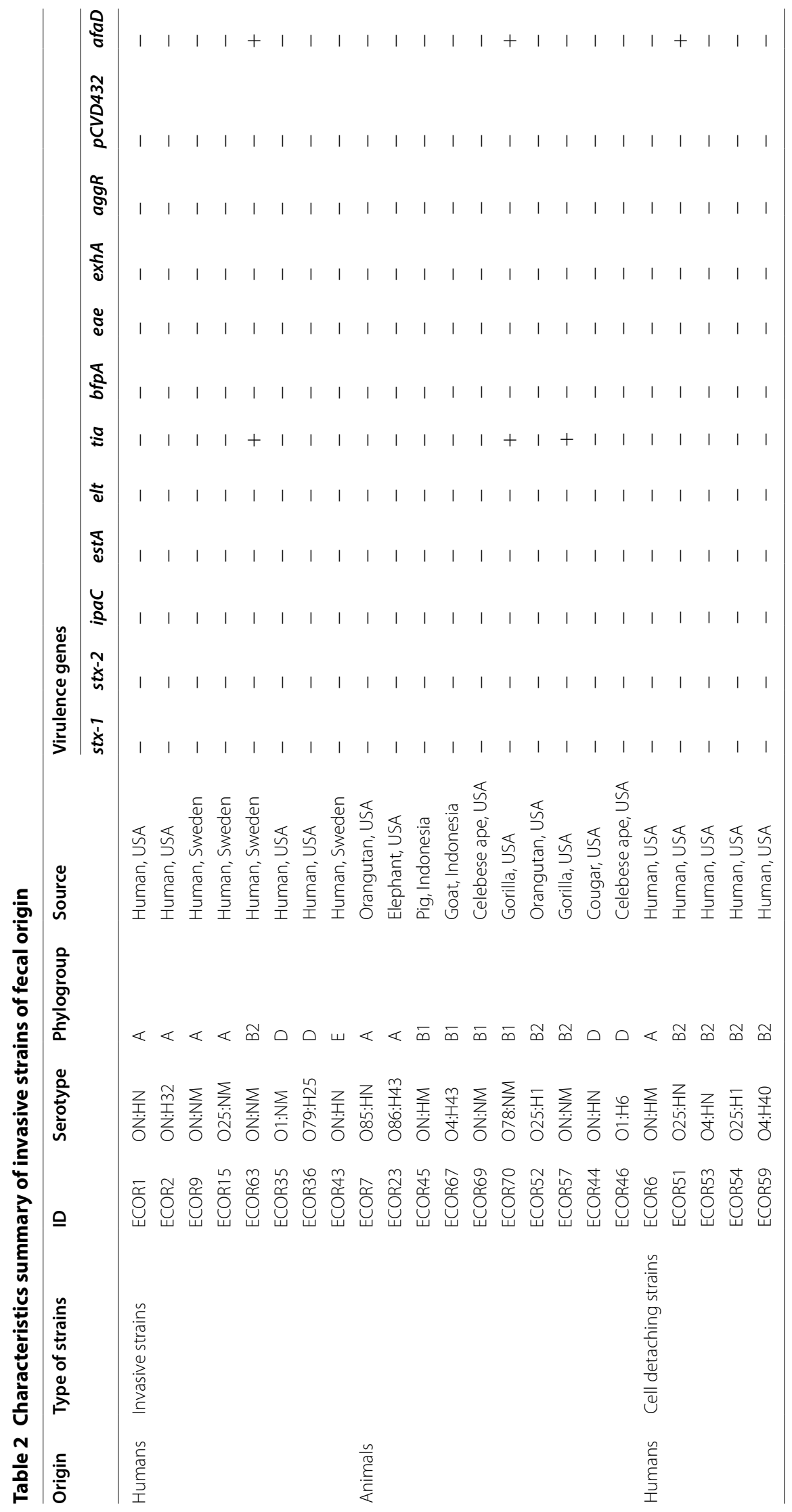


Table 3 Capacity of adhesion in I-407 cells and survival and replication in macrophages among the 15 invasive strains form the ECOR collection

\begin{tabular}{|c|c|c|c|}
\hline & ECOR strains & Mean adhesion index & $\begin{array}{l}\text { Mean of bacteria recovered } \\
\text { at } 1 \text { and } 24 \mathrm{~h} \text { postinfection } \\
(\%)\end{array}$ \\
\hline \multirow[t]{15}{*}{ Invasive strains } & ECOR1 & $197.89 \pm 29.77$ & $387.47 \% \pm 236.00 \%$ \\
\hline & ECOR35 & $210.53 \pm 208.41$ & $881.36 \% \pm 295.06 \%$ \\
\hline & ECOR52 & $73.26 \pm 2.38$ & $133.33 \%$ \\
\hline & ECOR2 & $111.58 \pm 32.75$ & $168.72 \% \pm 5.67 \%$ \\
\hline & ECOR36 & $145.26 \pm 68.48$ & $511.41 \% \pm 70.89 \%$ \\
\hline & ECOR43 & $82.11 \pm 20.84$ & $114.06 \% \pm 142.24 \%$ \\
\hline & ECOR44 & $334.74 \pm 229.25$ & $255.70 \% \pm 35.56 \%$ \\
\hline & ECOR45 & $94.74 \pm 20.84$ & $314.08 \% \pm 268.26 \%$ \\
\hline & ECOR46 & $92.63 \pm 17.86$ & $70.42 \%$ \\
\hline & ECOR7 & $170.53 \pm 74.43$ & $74.51 \%$ \\
\hline & ECOR9 & $157.89 \pm 56.57$ & $152.00 \%$ \\
\hline & ECOR15 & $153.68 \pm 44.66$ & $279.07 \%$ \\
\hline & ECOR23 & $260.63 \pm 48.23$ & $395.48 \%$ \\
\hline & ECOR67 & $67.37 \pm 23.82$ & $361.90 \%$ \\
\hline & ECOR69 & $117.89 \pm 41.68$ & $887.64 \%$ \\
\hline \multirow[t]{2}{*}{ Noninvasive strains } & E. coli K12 & $51.58 \pm 16.38$ & $24.59 \% \pm 2.84$ \\
\hline & E. coli Nissle & $32.21 \pm 8.30$ & $87.78 \% \pm 131.98 \%$ \\
\hline \multirow[t]{2}{*}{ Invasive strains } & AIEC LF82 & $166.32 \pm 20.84$ & $220.59 \%$ \\
\hline & AlEC NRG857C & $54.32 \pm 4.17$ & $194.90 \% \pm 39.93$ \\
\hline
\end{tabular}

invasive strains identified in this study, 5 belong to the phylogroup A, 3 to the phylogroup B1, 1 to the phylogroup B2, 3 to the phylogroup D and 1 to the phylogroup E. It has been shown that E. coli belonging to $\mathrm{B} 2$ and D phylogroups possess higher numbers of virulence genes than do A and B1 phylogroups. However, recently, no association was found between the phylogenetic background and the occurrence of diarrhea in calves [23]. The majority of AIEC strains isolated to date, coming from diseased human or animals, belong to the $\mathrm{B} 2$ phylogroup $[10,11,15,17,18]$. AIEC strains isolated from non-IBD controls (mainly patients suffering from rectorrhagia, hemorrhoids, irritable bowel syndrome, or diverticulitis) also mainly belong to the $\mathrm{B} 2$ phylogroup [10]. We showed here that AIEC strains isolated from healthy individuals, either humans or animals, mainly belong to other phylogroups.

Some studies have reported virulence determinant genes and cytotoxic profiles in E. coli strains from the ECOR collection [24-27]. Strains revealed to be invasive and capable of detaching I-407 cells were found to express some virulent genes such as pyelonephritis associated pili (pap), S-family adhesions (sfa), hemolysin ( $h l y)$, long polar fimbriae (lpf), and secreted autotransporter toxin (sat). Among the 13 adherent and invasive strains, 10 are known to express at least one of these genes (ECOR 2, 35, 36, 43, 23, 45, 67, 69, 52 and 44) and among the five cell-detaching strains, three harbor at least one of these virulence determinants (ECOR 51, 53 and 54) (Table 4). Some of these genes were also found in AIEC strains isolated from biopsies of both IBD and nonIBD patients. Martinez et al. showed that of a total of 16 AIEC strains recovered from biopsies of IBD patients, 8 express papC gene, 2 express $s f a, 4$ express hlya, and all fimH. AIEC strains from non-IBD patients $(\mathrm{n}=6)$ also express these genes, 4 were positive for papC, 2 for $s f a, 2$ for hlya and all for fimH [10].

Our work showed for the first time the detection of AIEC strains in healthy animal hosts; one from a healthy orangutan, one from a healthy elephant in captivity, one from a healthy celebese ape in captivity, one from a healthy pig, one from a healthy cougar and one from a healthy goat. These results provide further support for the absence of host specificity of this pathotype [28]. Further studies analyzing the prevalence of AIEC in wellcharacterized diseased and healthy animals are needed in order to detect putative reservoirs of AIEC strains and to evaluate the dimension of the risk with respect to the implementation of prevention and control measures and to public health.

To conclude, this study showed a prevalence of asymptomatic intestinal carriage of invasive pathogenic E. coli, 


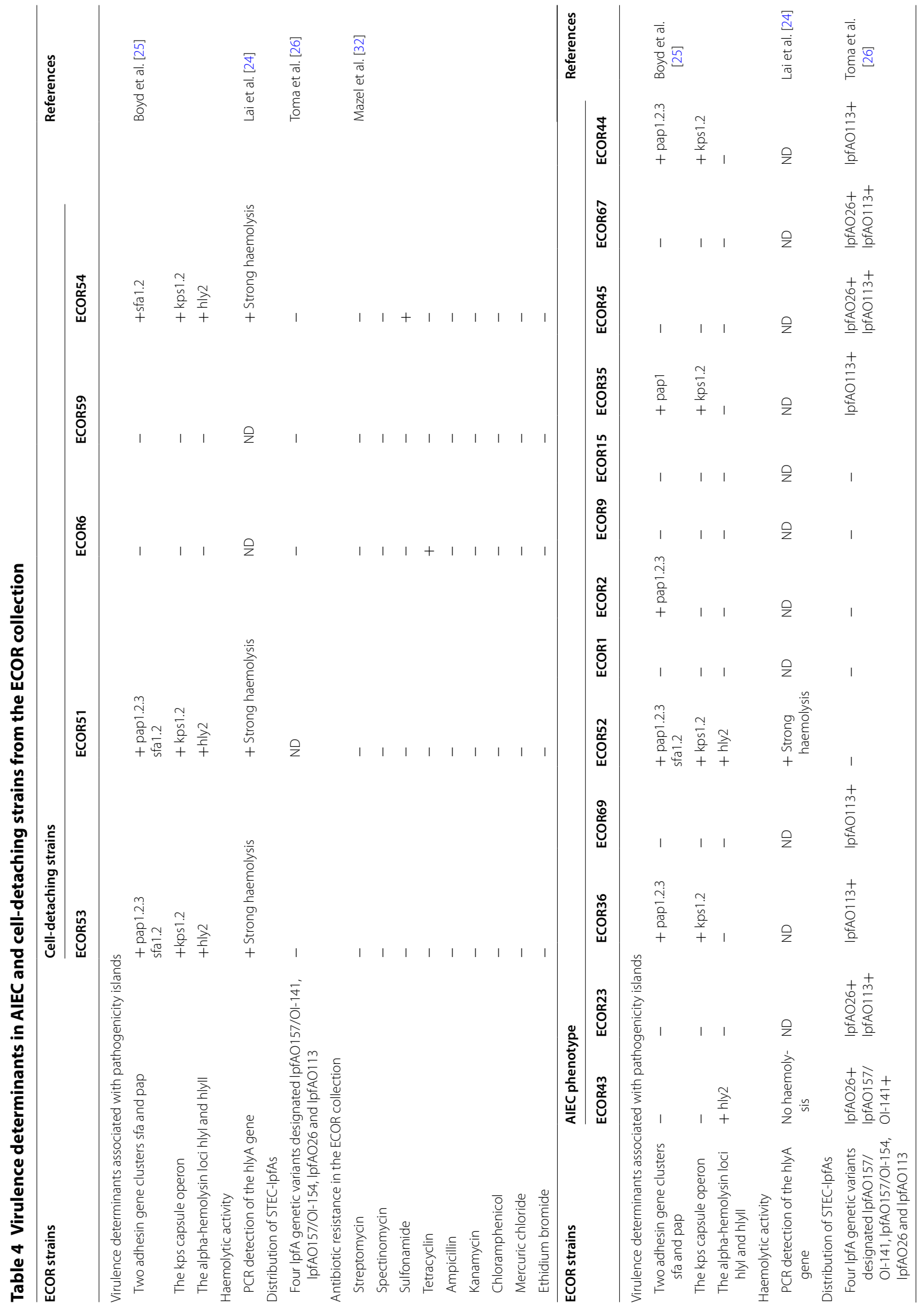




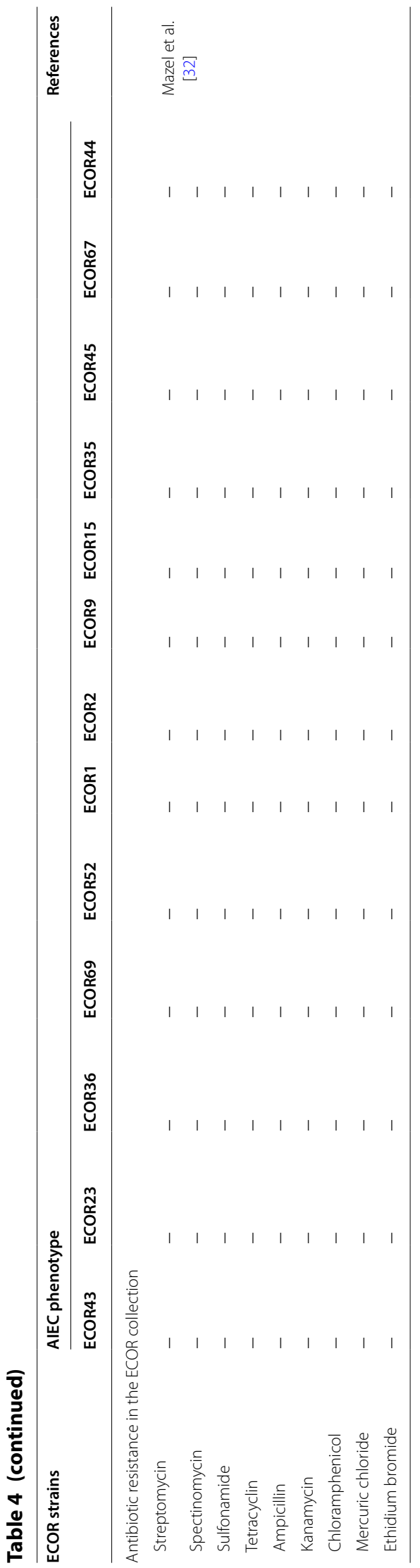


supporting the argument that AIEC may be considered as pathobiont $[9,16,29]$. Large-scale studies in humans (both $\mathrm{CD}$ and UC patients, irritable bowel disease patients and healthy individuals) are necessary for a better knowledge of AIEC distribution and are currently in progress in our laboratory. Our clinical study is consistent with these data, showing notably a high prevalence of AIEC in feces of healthy individuals (manuscript in preparation).

\section{Conclusions}

Our study has evaluated the prevalence of AIEC in the standard reference E. coli collection (ECOR). Among all the strains from the ECOR collection, $21 \%$ exhibited the AIEC phenotype, $24 \%$ were from healthy human origin and 19\% from different healthy animal hosts. This is of major interest from an epidemiological point of view, highlighting potential environmental niches and possible human transmission of AIEC and susceptibility in further inflammatory events in a healthy population.

\section{Methods}

\section{Bacterial strains}

Bacteria from the ECOR collection were kindly provided by Laurent Debarbieux (Institut Pasteur Paris) (Table 1). E. coli referent strains belonging to different pathogenic groups respectively ETEC (ATCC 35401), EHEC (ATCC 43895), EPEC (ATCC 43887), EAEC (ATCC 33780), EIEC (ATCC 43893), DAEC (AfaA30, kindly provided by Pr Eric Oswald, IRSD, INSERM UMR 1220, Toulouse, France) were used as positive controls in PCR genotyping; while $E$. coli $\mathrm{K} 12$ was used as a negative control. $E$. coli ATCC 25922 was used as a positive control for the gentamicin susceptibility assay. Bacteria were routinely grown on Luria-Bertani (LB) agar plates or in LB broth at $37^{\circ} \mathrm{C}$.

\section{Gentamicin susceptibility assay}

All the strains were assessed for their susceptibility to gentamicin by applying the in vitro diffusion method. Agar plates were inoculated with a 0.5 McFarland bacterial suspension. Then, gentamicin discs (Oxoid, $10 \mu \mathrm{g}$ ) were placed in the inoculated media and incubated at $37{ }^{\circ} \mathrm{C}$ for $24 \mathrm{~h}$. The susceptibility of the bacteria to gentamicin was determined by measurement of the diameters of the inhibition zones surrounding the discs in millimeters according EUCAST values. A control standard strain (E. coli ATCC 25922) for which the susceptibility to antimicrobial agents is known is included in the test to validate the assay [30].

\section{Cells}

Intestine-407 cell lines (I-407, ATCC accession number CCL- $6^{\mathrm{TM}}$ ) were used to determine bacterial invasiveness. I-407 cells were maintained in Basal medium Eagle (BME, Thermofisher, France) with $10 \%$ heat-inactivated fetal calf serum (Euroclone Italy) supplemented with $1 \%$ Glutamax and $1 \%$ penicillin/streptomycin (Thermofisher, France), in $5 \% \mathrm{CO}_{2}$ atmosphere at $37^{\circ} \mathrm{C}$.

\section{Adhesion and invasion assays in epithelial cells Intestine-407}

For AIEC identification, adhesion and invasion assays, based on gentamicin protection, were performed according to a previously described method $[6,15,21,22]$. 24-well plates containing $4 \times 10^{5}$ cells/well incubated for $20 \mathrm{~h}$ without antibiotics were infected with the E. coli strains at a multiplicity of infection of 10 during $3 \mathrm{~h}$ of incubation time. For the bacterial adhesion assays, the cell monolayers were washed with phosphate-buffered saline and then lysed with $1 \%$ Triton X-100. Adherent bacteria were quantified by plating them on LB agar. Plating was performed over a maximum period of $30 \mathrm{~min}$ in order to avoid bacterial lysis by Triton X-100. Adherence ability (I_ADH) was determined by calculating the mean number of bacteria per cell. For the bacterial invasion assays, cells were washed twice with phosphate buffer saline (PBS), and fresh cell culture medium containing $100 \mu \mathrm{g} \mathrm{ml}^{-1}$ of gentamicin was added for $1 \mathrm{~h}$ to kill extracellular bacteria. Cells were then washed three times with PBS and $1 \mathrm{ml}$ of $1 \%$ Triton X-100 was added in each well for 5 min to lyse the eukaryotic cells. After cell lysis, the number of intracellular bacteria was determined by plating. The invasive ability was expressed as the percentage of intracellular E. coli recovered from the initial inoculum, taken as $100 \%$. An isolate was considered invasive when invasion was $\geq 0.1 \%$. Each experiment was done in triplicate. The non-invasive strains of E. coli $\mathrm{K} 12$ and $E$. coli Nissle and the invasive AIEC LF82 and AIEC NRG857c strains were used as negative and positive control in each experiment.

\section{Survival and replication in $\mathrm{J774}$ macrophages}

The macrophage-like J774A.1 cell line (ATCC TIB-67) was used as a model in $E$. coli survival and replication assays. E. coli isolates with known adherence and invasion properties were checked for their ability to survive and replicate inside macrophages. Briefly, macrophages were seeded at $4 \times 10^{5}$ cells per well in two 24-well plates and incubated for $20 \mathrm{~h}$. After incubation, the medium was replaced with fresh medium and bacteria were 
seeded at a multiplicity of infection of 100 . To promote internalization of bacteria by the macrophages, the samples were centrifuged at $1000 \mathrm{rpm}$ for $10 \mathrm{~min}$ and incubated for an additional 10 min at $37{ }^{\circ} \mathrm{C}$ with $5 \% \mathrm{CO}_{2}$. Nonphagocytosed bacteria were killed with gentamicin. Intracellular bacteria were quantified in the same manner as described for the invasion assays after 1 and $24 \mathrm{~h}$ of infection. The results are expressed as the mean percentages of bacteria recovered at 1 and $24 \mathrm{~h}$ postinfection: I_REPL $(\%)=\left(\mathrm{CFU} \mathrm{ml}{ }^{-1}\right.$ at $24 \mathrm{~h} / \mathrm{CFU} \mathrm{ml}{ }^{-1}$ at $\left.1 \mathrm{~h}\right) \times 100$. Those strains with an I_INV of $>0.1$ and an I_REPL of $>100 \%$ were classified as AIEC strains in the present study. All assays were performed in duplicate.

\section{Virulence genotyping by polymerase chain reaction (PCR)}

DNA was extracted from bacteria by suspending one bacterial colony in $50 \mu \mathrm{l}$ of deionized water, boiling the suspension for $10 \mathrm{~min}$, and centrifuging it at $10,000 \times g$ for $1 \mathrm{~min}$. The supernatant was then used as the DNA template for PCR.

The presence of 12 virulence genes specifically associated with diarrheagenic E. coli pathotypes (EPEC, ETEC, EIEC, EHEC, DAEC, EAEC), and uropathogenic E. coli (UPEC) was analyzed (Additional file 1: Table S1) [8, 31]. E. coli reference strains were used as positive controls.

Adherent/invasive bacteria able to survive and to multiply within macrophage, without expressing virulence genes associated with diarrheagenic E. coli pathotypes and uropathogenic E. coli were considered as AIEC strains.

\section{Additional file}

Additional file 1: Table S1. Primers used for E. coli virulence genes detection.

\begin{abstract}
Abbreviations
AIEC: adherent invasive Escherichia coli; BME: Basal medium eagle; CD: Crohn's disease; ECOR: Escherichia coli Reference Collection; FCS: Fetal calf serum; I-407: Intestine-407 cell lines; IBD: inflammatory bowel disease; IEC: intestinal epithelial cells; LB: Luria Bertani; MLEE: multilocus enzyme electrophoresis; PBS: phosphate buffer saline; PCR: polymerase chain reaction; S: susceptible; TNF: tumor necrosis factor; UC: ulcerative colitis; USA: United States of America.
\end{abstract}

\section{Authors' contributions}

OR, MT and CV designed, performed and analyzed experiments. PD and LD conceived and designed the project. OR, MT, CN interpreted data. OR and CN wrote the manuscript. PD, LD, CN and BP supervised the study. BF, CN and CV critically revised the manuscript. PD and CN obtained funding. All authors read and approved the final manuscript.

\section{Author details}

${ }^{1}$ Lille Inflammation Research International Center, UMR 995 Inserm, Lille University, CHRU Lille, Lille, France. ${ }^{2}$ Centre de Biologie Pathologie Génétique, CHU Lille, Lille, France. ${ }^{3}$ Service des Maladies de l'Appareil Digestif et de la Nutrition, Hôpital Claude Huriez, CHU Lille, 59037 Lille, France. ${ }^{4}$ Laboratoire de Bactériologie, 3, Rue de Pr. Laguesse, B.P. 83, 59006 Lille Cedex, France.

\section{Acknowledgements}

We are grateful to Dr. Laurent Debarbieux (Institut Pasteur Paris) for the gift of the ECOR collection strains. We also thank Pr Eric Oswald for the E. coli referent strains belonging to different pathogenic groups.

\section{Competing interests}

The authors declare that they have no competing interests.

\section{Availability of data and materials \\ Not applicable.}

\section{Consent for publication}

Not applicable.

Ethics approval and consent to participate

Not applicable.

Funding

We would like to thank DigestScience foundation for their financial support.

\section{Publisher's Note}

Springer Nature remains neutral with regard to jurisdictional claims in published maps and institutional affiliations.

Received: 16 March 2018 Accepted: 23 May 2018

Published online: 14 June 2018

\section{References}

1. Kaplan GG, Ng SC. Understanding and preventing the global increase of inflammatory bowel disease. Gastroenterology. 2017;152:313-21.

2. de Souza HSP, Fiocchi C. Immunopathogenesis of IBD: current state of the art. Nat Rev Gastroenterol Hepatol. 2016;13:13-27.

3. Xavier RJ, Podolsky DK. Unravelling the pathogenesis of inflammatory bowel disease. Nature. 2007:448:427-34.

4. Sartor RB, Wu GD. Roles for intestinal bacteria, viruses, and fungi in pathogenesis of inflammatory bowel diseases and therapeutic approaches. Gastroenterology. 2017;152:327-39.

5. Swidsinski A, Ladhoff A, Pernthaler A, Swidsinski S, Loening-Baucke V, Ortner M, Weber J, Hoffmann U, Schreiber S, Dietel M, Lochs H. Mucosal flora in inflammatory bowel disease. Gastroenterology. 2002;122:44-54.

6. Darfeuille-Michaud A, Boudeau J, Bulois P, Neut C, Glasser A-L, Barnich N, Bringer M-A, Swidsinski A, Beaugerie L, Colombel J-F. High prevalence of adherent-invasive Escherichia coli associated with ileal mucosa in Crohn's disease. Gastroenterology. 2004;127:412-21.

7. Palmela C, Chevarin C, Xu Z, Torres J, Sevrin G, Hirten R, Barnich N, Ng SC, Colombel J-F. Adherent-invasive Escherichia coli in inflammatory bowel disease. Gut. 2017;67:574-87.

8. Martin HM, Campbell BJ, Hart CA, Mpofu C, Nayar M, Singh R, Englyst H, Williams HF, Rhodes JM. Enhanced Escherichia coli adherence and invasion in Crohn's disease and colon cancer. Gastroenterology. 2004;127:80-93.

9. Conte M, Longhi C, Marazzato M, Conte A, Aleandri M, Lepanto M, Zagaglia C, Nicoletti M, Aloi M, Totino V, Palamara A, Schippa S. Adherentinvasive Escherichia coli (AIEC) in pediatric Crohn's disease patients: phenotypic and genetic pathogenic features. BMC Res Notes. 2014;7:748.

10. Martinez-Medina M, Aldeguer X, Lopez-Siles M, González-Huix F, LópezOliu C, Dahbi G, Blanco JE, Blanco J, Garcia-Gil LJ, Darfeuille-Michaud A. Molecular diversity of Escherichia coli in the human gut: new ecological evidence supporting the role of adherent-invasive E. coli (AIEC) in Crohn's disease. Inflamm Bowel Dis. 2009;15:872-82.

11. Céspedes S, SaitzW, Del Canto F, De la Fuente M, Quera R, Hermoso M, Muñoz R, Ginard D, Khorrami S, Girón J, Assar R, Rosselló-Mora R, Vidal RM. Genetic diversity and virulence determinants of Escherichia coli strains isolated from patients with Crohn's disease in Spain and Chile. Front Microbiol. 2017;8:639.

12. Baumgart $M$, Dogan $B$, Rishniw $M$, Weitzman $G$, Bosworth $B$, Yantiss $R$, Orsi RH, Wiedmann M, McDonough P, Kim SG, Berg D, Schukken Y, Scherl E, Simpson KW. Culture independent analysis of ileal mucosa reveals a 
selective increase in invasive Escherichia coli of novel phylogeny relative to depletion of Clostridiales in Crohn's disease involving the ileum. ISME J. 2007;1:403-18.

13. Sasaki M, Sitaraman SV, Babbin BA, Gerner-Smidt P, Ribot EM, Garrett N, Alpern JA, Akyildiz A, Theiss AL, Nusrat A, Klapproth JMA. Invasive Escherichia coli are a feature of Crohn's disease. Lab Invest. 2007;87:1042-54.

14. Nash JH, Villegas A, Kropinski AM, Aguilar-Valenzuela R, Konczy P, Mascarenhas M, Ziebell K, Torres AG, Karmali MA, Coombes BK. Genome sequence of adherent-invasive Escherichia coli and comparative genomic analysis with other E. coli pathotypes. BMC Genomics. 2010;11:667.

15. Martinez-Medina M, Mora A, Blanco M, López C, Alonso MP, Bonacorsi S, Nicolas-Chanoine M-H, Darfeuille-Michaud A, Garcia-Gil J, Blanco J. Similarity and divergence among adherent-invasive Escherichia coli and extraintestinal pathogenic E. coli strains. J Clin Microbiol. 2009;47:3968-79.

16. Martinez-Medina M, Garcia-Gil LJ. Escherichia coli in chronic inflammatory bowel diseases: an update on adherent invasive Escherichia coli pathogenicity. World J Gastrointest Pathophysiol. 2014;3:213-27.

17. Simpson KW, Dogan B, Rishniw M, Goldstein RE, Klaessig S, McDonough PL, German AJ, Yates RM, Russell DG, Johnson SE, Berg DE, Harel J, Bruant G, McDonough SP, Schukken YH. Adherent and invasive Escherichia coli is associated with granulomatous colitis in boxer dogs. Infect Immun. 2006;74:4778-92.

18. Martinez-Medina M, Garcia-Gil J, Barnich N, Wieler LH, Ewers C. Adherentinvasive Escherichia coli phenotype displayed by intestinal pathogenic E. coli strains from cats, dogs, and swine. Appl Environ Microbiol. 2011:77:5813-7.

19. Ochman H, Selander RK. Standard reference strains of Escherichia coli from natural populations. J Bacteriol. 1984;157:690-3.

20. Clermont O, Cordevant C, Bonacorsi S, Marecat A, Lange M, Bingen E. Automated ribotyping provides rapid phylogenetic subgroup affiliation of clinical extraintestinal pathogenic Escherichia coli strains. J Clin Microbiol. 2001;39:4549-53.

21. Drouet M, Vignal C, Singer E, Djouina M, Dubreuil L, Cortot A, Desreumaux P, Neut C. AlEC colonization and pathogenicity: influence of previous antibiotic treatment and preexisting inflammation. Inflamm Bowel Dis. 2012;18:1923-31.

22. Boudeau J, Glasser AL, Masseret E, Joly B, Darfeuille-Michaud A. Invasive ability of an Escherichia coli strain isolated from the ileal mucosa of a patient with Crohn's disease. Infect Immun. 1999;67:4499-509.
23. Coura FM, de Araújo Diniz S, Mussi JMS, Silva MX, Lage AP, Heinemann MB. Characterization of virulence factors and phylogenetic group determination of Escherichia coli isolated from diarrheic and non-diarrheic calves from Brazil. Folia Microbiol. 2017;62:139-44.

24. Lai XH, Wang SY, Uhlin BE. Expression of cytotoxicity by potential pathogens in the standard Escherichia coli collection of reference (ECOR) strains. Microbiology. 1999;145:3295-303.

25. Boyd EF, Hartl DL. Chromosomal regions specific to pathogenic isolates of Escherichia coli have a phylogenetically clustered distribution. J Bacteriol. 1998;180:1159-65.

26. Toma C, Higa N, lyoda S, Rivas M, Iwanaga M. The long polar fimbriae genes identified in Shiga toxin-producing Escherichia coli are present in other diarrheagenic E. coli and in the standard E. coli collection of reference (ECOR) strains. Res Microbiol. 2006;157:153-61.

27. Restieri C, Garriss G, Locas M-C, Dozois CM. Autotransporter-encoding sequences are phylogenetically distributed among Escherichia coli clinical isolates and reference strains. Appl Environ Microbiol. 2007;73:1553-62.

28. Dogan B, Suzuki H, Herlekar D, Sartor RB, Campbell BJ, Roberts CL, Stewart K, Scherl EJ, Araz Y, Bitar PP, Lefébure T, Chandler B, Schukken YH, Stanhope MJ, Simpson KW. Inflammation-associated adherent-invasive Escherichia coli are enriched in pathways for use of propanediol and iron and M-cell translocation. Inflamm Bowel Dis. 2014;20:1919-32.

29. Chassaing B, Koren O, Carvalho FA, Ley RE, Gewirtz AT. AIEC pathobiont instigates chronic colitis in susceptible hosts by altering microbiota composition. Gut. 2014;63:1069-80.

30. European Committee on Antimicrobial Susceptibility Testing. http:// www.eucast.org/clinical_breakpoints/.

31. Cabal A, Gómez-Barrero S, Porrero C, Bárcena C, López G, Cantón R, Gortázar C, Domínguez L, Álvarez J. Assessment of virulence factors characteristic of human Escherichia coli pathotypes and antimicrobial resistance in 0157:H7 and non-O157:H7 isolates from livestock in Spain. Appl Environ Microbiol. 2013;79:4170-2.

32. Mazel D, Dychinco B, Webb V-A, Davies J. Antibiotic resistance in the ECOR collection: integrons and identification of a novel aad gene. Antimicrob. Agents Chemother. 2000;44:1568-74
Ready to submit your research? Choose BMC and benefit from:

- fast, convenient online submission

- thorough peer review by experienced researchers in your field

- rapid publication on acceptance

- support for research data, including large and complex data types

- gold Open Access which fosters wider collaboration and increased citations

- maximum visibility for your research: over 100M website views per year

At BMC, research is always in progress.

Learn more biomedcentral.com/submissions 